Pacific Journal of Mathematics

DIFFERENTIABILITY OF SOLUTIONS OF ORDINARY
DIFFERENTIAL EQUATIONS IN HILBERT SPACE 


\title{
DIFFERENTIABILITY OF SOLUTIONS OF ORDINARY DIFFERENTIAL EQUATIONS IN HILBERT SPACE
}

\author{
AVNER FrIEDMAN
}

Consider the differential equation

$$
\frac{1}{i} \frac{d u}{d t}-A(t) u=f(t)(a<t<b)
$$

where $u(t), f(t)$ are elements of a Hilbert space $E$ and $A(t)$ is a closed linear operator in $E$ with a domain $D(A)$ independent of $t$ and dense in $E$. Denote by $C^{m}(a, b)$ the set of functions $v(t)$ with values in $E$ which have $m$ strongly continuous derivatives in $(a, b)$. Introducing the norm

$$
|v|_{m}=\left\{\sum_{j=0}^{m} \int_{a}^{b}\left|v^{(j)}(t)\right|^{2} d t\right\}^{1 / 2}
$$

where $|v(t)|$ is the $E$-norm of $v(t)$, we denote by $H^{m}(a, b)$ the completion with respect to the norm (1.2) of the subset of functions in $C^{m}(a, b)$ whose norm is finite. Set $H^{m}=H^{m}(-\infty, \infty)$ and denote by $H_{0}^{m}$ the subset of functions in $H^{m}$ which have compact support. The solutions $u(t)$ of $(1.1)$ are understood in the sense that $u(t) \in H^{1}\left(a^{\prime}, b^{\prime}\right)$ for any $a<a^{\prime}<b^{\prime}<b$.

Theorem 1. Assume that, for each $a<t<b$, the resolvent $R(\lambda, A(t))=(\lambda-A(t))^{-1}$ of $A(t)$ exists for all real $\lambda,|\lambda| \geqq N(t)$, and that

$$
|R(\lambda, A(t))| \leqq \frac{C(t)}{|\lambda|} \text { if } \lambda \text { real, }|\lambda| \geqq N(t),
$$

where $N(t), C(t)$ are constants. Assume next that for each $s \in(a, b), A^{-1}(s)$ exists and

(1.4) $A(t) A^{-1}(s)$ has $m$ uniformly continuous $t$-derivatives,

for $a<t<b$, where $m$ is any integer $\geqq 1$. If $u$ is $a$ solution of (1.1) and if $f \in H^{m}(a, b)$, then $u \in H^{m+1}\left(a^{\prime}, b^{\prime}\right)$ for any $a<a^{\prime}<b^{\prime}<b$.

Theorem 2. If the assumptions of Theorem 1 hold with $m=\infty$, if $A(t) A^{-1}(s)$ is analytic in $t(a<t<b)$ for each $s \in(a, b)$, and if $f(t)$ is analytic in $(a, b)$, then $u(t)$ is also analytic in $(a, b)$.

In case $E$ is a Banach space, an analogue of Theorem 1 was proved by Sobolevski [3] and Tanabe [4] and an analogue of Theorem 2 was proved by Sobolevski [3] and Komatzu [2], but all these authors

Received May 1, 1964. This work was partially supported by the Alfred P. Sloan Foundation and by the National Science Foundation Grant G14876. 
assume a stronger condition on the resolvent, namely, they assume that (1.3) holds for all complex $\lambda$ with $\operatorname{Im}(\lambda) \geqq 0$. On the other hand analogs of Theorems 1, 2 were proved by Agmon and Nirenberg [1] (for $E$ a Banach space) under weaker bounds on $R(\lambda, A)$, but only in the case where $A(t) \equiv A$ is independent of $t$. It was shown in [1] that the condition (1.3) is necessary if $u \in C^{m+1}(a, b)$ whenever $f \in C^{m}(a, b)$.

Before proving Theorem 1 we wish to observe that (1.4) implies that $A(s) A^{-1}(t)$ has $m$ uniformly continuous $t$-derivatives.

Indeed, setting $B(t)=A(t) A^{-1}(s)$ and multiplying both sides of $B(t+h)-B(t)=B(t, h) h$ (here $\|B(t, h)\|$ is bounded independently of $h,|h|$ small) by $B^{-1}(t), B^{-1}(t+h)$, we find that $\left\|B^{-1}(t)\right\|$ is locally bounded. We further find that $B^{-1}(t)$ is continuous in $t$ and also differentiable, and $\left(B^{-1}(t)\right)^{\prime}=B^{-1}(t) B^{\prime}(t) B^{-1}(t) ;(1.5)$ now easily follows.

Writing $A(t) A^{-1}(s)=A(t) A^{-1}(\bar{s})\left[A(\bar{s}) A^{-1}(s)\right]$ we see that if (1.4) holds for one particular $s=\bar{s}$ and if $A(\bar{s}) A^{-1}(s)$ is a bounded operator for each $s$, then (1.4) holds.

2. Proof of Theorem 1. Consider first the case $A(t) \equiv A$.

Lemma 1. If $f \in H_{0}^{m}(m \geqq 0), u \in H_{0}^{1}$ and (1.1) holds for $-\infty<$ $t<\infty$, then $u \in H_{0}^{m+1}$ and

$$
|u|_{m+1} \leqq C\left(|f|_{m}+|u|_{0}\right)
$$

where $C$ depends only on $A, m$.

Proof. Taking the Fourier transform of (1.1) we get $(\lambda-A) \hat{u}(\lambda)=$ $\hat{f}(\lambda)$, hence

$$
\begin{aligned}
\sqrt{2 \pi} u(t) & =\int_{-N}^{N} e^{i \lambda t} \hat{u}(\lambda) d \lambda+\int_{-\infty}^{-N} e^{i \lambda t} R(\lambda, A) \hat{f}(\lambda) d \lambda+\int_{N}^{\infty} e^{i \lambda t} R(\lambda, A) \hat{f}(\lambda) d \lambda \\
& \equiv u_{1}+u_{2}+u_{3} .
\end{aligned}
$$

By Schwarz's inequality and Plancherel's theorem,

$$
\left|u_{1}\right|_{m+1}^{2} \leqq C \int_{-N}^{N}|\widehat{u}(\lambda)|^{2} d \lambda \leqq C|u|_{0}^{2}
$$

where various constants depending only on $A, m$ are denoted by $C$. Next, if $f$ is sufficiently smooth then

$$
u_{2}^{(j)}(t)=\int_{-\infty}^{-N} e^{i \lambda t}(i \lambda)^{j} R(\lambda, A) \hat{f}(\lambda) d \lambda(0 \leqq j \leqq m+1),
$$

so that by Plancherel's theorem and (1.3), 


$$
\left|u_{2}\right|_{m+1}^{2} \leqq C \sum_{j=1}^{m+1} \int_{-\infty}^{-N}\left|\lambda^{j-1} \hat{f}(\lambda)\right|^{2} d \lambda \leqq C|f|_{m}^{2} .
$$

If now $f$ is only assumed to belong to $H_{0}^{m}$, then the inequality $\left|u_{2}\right|_{m+1}^{2} \leqq C|f|_{m}^{2}$ follows by approximating $f$ by sufficiently smooth functions (for instance, by employing mollifiers and using the fact that "weak" derivatives are also "strong" derivatives). Since a similar inequality holds for $u_{3}, u \in H_{0}^{m+1}$ and (2.1) holds.

From (2.1), (1.3) we get

$$
|A u|_{m} \leqq C\left(|f|_{m}+|u|_{0}\right) \text {. }
$$

LEMma 2. Let the assumptions of Theorem 1 hold for $(a, b)=$ $(-\infty, \infty)$, let the derivatives in (1.4) be uniformly bounded in $t$, and let $\|B(t)\|<\delta$ where $B(t)=[A(t)-A(s)] A^{-1}(s)$. If $u$ is a solution of (1.1) in $(-\infty, \infty)$, if $f \in H_{0}^{m}(m \geqq 0), u \in H_{0}^{1}, A(s) u \in H_{0}^{m}$, and if $\delta$ is sufficiently small (depending only on $A(s), m$ ), then $u \in H_{0}^{m+1}$ and

$$
|u|_{m+1} \leqq C\left(|f|_{m}+|u|_{0}\right) .
$$

Proof. $u$ satisfies

$$
\frac{1}{i} \frac{d u}{d t}-A(s) u=B(t) A(s) u(t)+f(t),
$$

from which it follows that $u \in H_{0}^{m+1}$. Applying (2.2) with $m=0$ and taking $\delta<1 / 2 C\left(C\right.$ as in (2.2)) we get $|A(s) u|_{0} \leqq C\left(|f|_{0}+|u|_{0}\right)$. Next applying (2.2) with $m=1$ and using the last inequality we find that $|A(s) u|_{1} \leqq C\left(|f|_{1}+|u|_{0}\right)$.

Proceeding step by step one gets

$$
|A(s) u|_{m} \leqq C\left(|f|_{m}+|u|_{0}\right) \text {. }
$$

(2.3) follows from (2.4), (2.5).

Setting $v_{h}(t)=[v(t+h)-v(t)] / h$, we have the following

LemmA 3. Let $u \in H_{0}^{0}, u \in H^{m+1}(m \geqq 0)$ if and only if $u_{h} \in H^{m}$ for all $h$ sufficiently small and $\left|u_{h}\right|_{m} \leqq M$, and, in that case, $|u|_{m+1} \leqq C M$ and $\left|u_{h}\right|_{m} \leqq C|u|_{m+1}$.

The lemma is well known in the special case where $u(t)$ is a complex-valued function. The proof in the present more general case can be given analogously, or also by expanding $u(t)$ in terms of a fixed orthonormal basis of $E$ and applying the special case to each component.

Lemma 4. Lemma 2 holds even if the assumption that $A(s) u \in H^{m}$ is dropped. 
Proof. Taking finite differences in (1.1) we get $\frac{1}{i} \frac{d u_{h}}{d t}-A(t) u_{h}=\left[A_{h}(t) A^{-1}(s)\right] A(s) u(t+h)+f_{h}(t) \equiv \varphi(t ; h)$.

Since $A(t) u \in H^{\circ}$ the same is true of $A(s) u$ (using (1.5)) and of $A(s) u_{h}$. Lemma 2 can then be applied to $u_{h}$ with $m=0$. We find (using Lemma 3) that $\left|u_{h}\right|_{1} \leqq C$; hence, by Lemma $3, u \in H^{2}$. Then $\mathrm{A}(t) u \in$ $H^{1}$ and we can proceed to apply Lemma 2 to $u_{h}$ with $m=1$. Thus, $u \in H^{3}$, etc.

Let $\zeta(t)$ be a $C^{\infty}$ function satisfying: $\zeta(t)=1$ if $|t-s|<\varepsilon$, $\zeta(t)=0$ if $|t-s|>2 \varepsilon$, where $\varepsilon$ is sufficiently small. $v=\zeta u$ satisfies

$$
\frac{1}{i} \frac{d v}{d t}-A(t) v=\zeta f+i \zeta^{\prime} u
$$

Applying Lemma 4 with $m=1$ we find that $u \in H^{2}(s-\varepsilon, s+\varepsilon)$. Similarly, by considering $v_{1}=\zeta_{1} u$ where $\zeta_{1}(t)=\zeta(2 t-s)$ and applying to it Lemma 4 with $m=2$, we find that $u \in H^{3}(s-(1 / 2) \varepsilon, s+(1 / 2) \varepsilon)$. Proceeding in this manner, step by step, we find that $u \in$ $H^{m+1}\left(s-\varepsilon_{1}, s+\varepsilon_{1}\right)$ for some $\varepsilon_{1}>0$. Since $s$ is an arbitrary point in $(a, b)$, the proof of Theorem 1 is complete.

REMARK. If $u \in H^{m+1}(a, b)$ then $u(t)$ is equal almost everywhere to (and therefore can be identified with) a function in $C^{m}(a, b)$.

3. Proof of Theorem 2. It suffices to prove analyticity in a small interval $\left(a^{\prime}, b^{\prime}\right)$. Furthermore, it suffices to show that for some fixed $s \in\left(a^{\prime}, b^{\prime}\right)$,

$$
\begin{aligned}
|A(s) u|_{m-1, \delta}+|u|_{m, \delta} \leqq & \frac{H_{0} H^{m}}{\delta^{m}} m ! \\
& \left(m=0,1, \cdots ; 0<\delta<\frac{b^{\prime}-a^{\prime}}{2}\right)
\end{aligned}
$$

where $|u|_{m, \delta}=\left[\int_{a^{\prime}+\delta}^{b^{\prime}-\delta}\left|u^{(m)}(t)\right|^{2} d t\right]^{1 / 2}$. The proof is by induction on $m$. To pass from $m$ to $m+1$ we differentiate (1.1) $m$ times and thus obtain

$$
\frac{1}{i} \frac{d u^{(m)}}{d t}-A(t) u^{(m)}=\sum_{j=0}^{m-1}\left({ }_{j}^{m}\right)\left[A^{(m-j)}(t) A^{-1}(s)\right] A(s) u^{(j)}(t)+f^{(m)}(t) \equiv \varphi_{m} .
$$

Let $\zeta(t)$ be a smooth function satisfying: $\zeta(t)=1$ if $a^{\prime}+\delta<t<b^{\prime}-\delta$, $\zeta(t)=0$ if $a^{\prime}<t<a^{\prime}+\delta^{\prime}$ or if $b^{\prime}-\delta^{\prime}<t<b^{\prime}$, and $\left|\zeta^{\prime}(t)\right| \leqq C /\left(\delta-\delta^{\prime}\right)$. $v=\zeta u^{(m)}$ satisfies 


$$
\frac{1}{i} \frac{d v}{d t}-A(t) v=\zeta \varphi_{m}+i \zeta^{\prime} u^{(m)}
$$

If $b^{\prime}-a^{\prime}$ is sufficiently small then we can apply (2.3), (2.5) (with $m=0)$ and thus obtain, if $\delta=\delta^{\prime}(1+1 / m)$ and if $H$ is sufficiently large (independently of $m, \delta$ ),

$$
|A(s) u|_{m, \delta}+|u|_{m+1, \delta} \leqq C \frac{H_{0} H^{m}}{\delta^{m+1}}(m+1) ! \leqq \frac{H_{0} H^{m+1}}{\delta^{m+1}}(m+1) ! ;
$$

use has been made of the inequalities

$$
\left|A^{(n)}(t) A^{-1}(s)\right|_{0}+\left|f^{(n)}\right|_{0} \leqq(\text { const. })^{n+1} n ! .
$$

\section{REFERENCES}

1. S. Agmon and L. Nirenberg, Properties of solutions of ordinary differential equations in Banach space, Comm. Pure Appl. Math. 16 (1963), 121-239.

2. H. Komatzu, Abstract analyticity in time and unique continuation property for solutions of parabolic equations, J. Facul. Sci. Univ. Tokyo, Sec. I, 9 (1961), 1-11.

3. P. E. Sobolevski, On equations of parabolic type in a Banach space, Trudy Moscow Math. Obsch. 10 (1961), 297-350.

4. H. Tanabe, On the equations of evolution in a Banach space, Osaka Math. J. 12 (1960), 363-376.

NORTHWESTERN UNIVERSITY 



\section{PACIFIC JOURNAL OF MATHEMATICS}

\section{EDITORS}

\section{H. SAMELSON}

Stanford University

Stanford, California

\section{R. M. BLUMenthaL \\ University of Washington \\ Seattle, Washington 98105}

*J. DugundjI

University of Southern California Los Angeles, California 90007

\section{RICHARD ARENS}

University of California

Los Angeles, California 90024

\section{ASSOCIATE EDITORS}
E. F. BECKENBACH
B. H. NeUManN
F. WOLF
K. YosIDA

\section{SUPPORTING INSTITUTIONS}

\author{
UNIVERSITY OF BRITISH COLUMBIA \\ CALIFORNIA INSTITUTE OF TECHNOLOGY \\ UNIVERSITY OF CALIFORNIA \\ MONTANA STATE UNIVERSITY \\ UNIVERSITY OF NEVADA \\ NEW MEXICO STATE UNIVERSITY \\ OREGON STATE UNIVERSITY \\ UNIVERSITY OF OREGON \\ OSAKA UNIVERSITY \\ UNIVERSITY OF SOUTHERN CALIFORNIA
}

\author{
STANFORD UNIVERSITY \\ UNIVERSITY OF TOKYO \\ UNIVERSITY OF UTAH \\ WASHINGTON STATE UNIVERSITY \\ UNIVERSITY OF WASHINGTON \\ AMERICAN MATHEMATICAL SOCIETY \\ CHEVRON RESEARCH CORPORATION \\ TRW SYSTEMS \\ NAVAL ORDNANCE TEST STATION
}

Mathematical papers intended for publication in the Pacific Journal of Mathematics should be typewritten (double spaced). The first paragraph or two must be capable of being used separately as a synopsis of the entire paper. It should not contain references to the bibliography. Manuscripts may be sent to any one of the four editors. All other communications to the editors should be addressed to the managing editor, Richard Arens at the University of California, Los Angeles, California 90024.

50 reprints per author of each article are furnished free of charge; additional copies may be obtained at cost in multiples of 50 .

The Pacific Journal of Mathematics is published monthly. Effective with Volume 16 the price per volume (3 numbers) is $\$ 8.00$; single issues, $\$ 3.00$. Special price for current issues to individual faculty members of supporting institutions and to individual members of the American Mathematical Society: $\$ 4.00$ per volume; single issues $\$ 1.50$. Back numbers are available.

Subscriptions, orders for back numbers, and changes of address should be sent to Pacific Journal of Mathematics, 103 Highland Boulevard, Berkeley 8, California.

Printed at Kokusai Bunken Insatsusha (International Academic Printing Co., Ltd.), No. 6, 2-chome, Fujimi-cho, Chiyoda-ku, Tokyo, Japan.

PUBLISHED BY PACIFIC JOURNAL OF MATHEMATICS, A NON-PROFIT CORPORATION

The Supporting Institutions listed above contribute to the cost of publication of this Journal, but they are not owners or publishers and have no responsibility for its content or policies.

* Paul A. White, Acting Editor until J. Dugundji returns. 


\section{Pacific Journal of Mathematics}

\section{Vol. 16, No. 2 December, 1966}

Loren N. Argabright, Invariant means on topological semigroups ........ 193

William Arveson, A theorem on the action of abelian unitary groups ...... 205

John Spurgeon Bradley, Adjoint quasi-differential operators of Euler

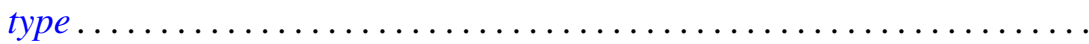

Don Deckard and Lincoln Kearney Durst, Unique factorization in power series rings and semigroups ........................... 239

Allen Devinatz, The deficiency index of ordinary self-adjoint differential operators..................................... 243

Robert E. Edwards, Operators commuting with translations ............ 259

Avner Friedman, Differentiability of solutions of ordinary differential equations in Hilbert space .............................. 267

Boris Garfinkel and Gregory Thomas McAllister, Jr., Singularities in a variational problem with an inequality ......................

Seymour Ginsburg and Edwin Spanier, Semigroups, Presburger formulas,

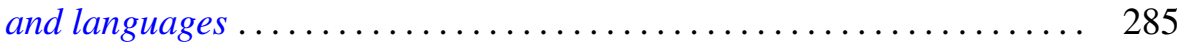

Burrell Washington Helton, Integral equations and product integrals . . . . . . 297

Edgar J. Howard, First and second category Abelian groups with the n-adic topology.........................................

Arthur H. Kruse and Paul William Liebnitz, Jr., An application of a family homotopy extension theorem to ANR spaces.

Albert Marden, I. Richards and Burton Rodin, On the regions bounded by homotopic curves

Willard Miller, Jr., A branching law for the symplectic groups ...

Marc Aristide Rieffel, A characterization of the group algebras of the finite

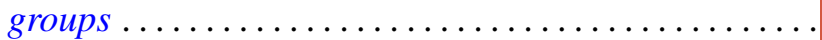

P. P. Saworotnow, On two-sided $H^{*}$-algebras

John Griggs Thompson, Factorizations of p-solvable groups ...

Shih-hsiung Tung, Harnack's inequalities on the classical Cartan

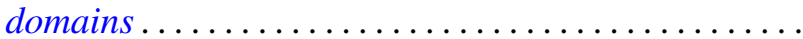

